\title{
Preparation and characterization of $x-$ ray mirrors with three single layers of a-C, B4C, and Ni onto two 820-mm long Si substrate
}

Michael Störmer, Frank Siewert, Jana Buchheim, Alexander Pilz, Marion Kuhlmann, et al.

Michael Störmer, Frank Siewert, Jana Buchheim, Alexander Pilz, Marion Kuhlmann, Elke Ploenjes, Kai Tiedtke, "Preparation and characterization of xray mirrors with three single layers of a-C, B4C, and Ni onto two $820-\mathrm{mm}$ long Si substrate," Proc. SPIE 9207, Advances in X-Ray/EUV Optics and Components IX, 92070H (5 September 2014); doi: 10.1117/12.2063017

EviE Event: SPIE Optical Engineering + Applications, 2014, San Diego, California, United States 


\title{
Preparation and characterization of $\mathrm{X}$-ray mirrors with three single layers of a-C, $\mathrm{B}_{4} \mathrm{C}$ and Ni onto two $820 \mathrm{~mm}$ long Si substrate
}

\author{
Michael Störmer*a , Frank Siewert ${ }^{\mathrm{b}}$, Jana Buchheim ${ }^{\mathrm{b}}$, Alexander Pilz ${ }^{\mathrm{c}}$, Marion Kuhlmann ${ }^{\mathrm{d}}$, Elke \\ Ploenjes ${ }^{\mathrm{d}}$, Kai Tiedtke ${ }^{\mathrm{d}}$ \\ ${ }^{a}$ Helmholtz-Zentrum Geesthacht (HZG), Institute of Materials Research, Max-Planck-Str. 1, D- \\ 21502 Geesthacht, Germany; \\ ${ }^{b}$ Helmholtz-Zentrum Berlin (HZB), Institute of Nanometre Optics and Technology, Albert-Einstein- \\ Str. 15, D-12489 Berlin, Germany; \\ 'Pilz-Optics, Enzianstr. 29, D-73485 Zöbingen-Unterscheidheim; \\ ${ }^{\mathrm{d}}$ Deutsches Elektronen-Synchrotron (DESY), FLASH, Notkestr. 85, D-22607 Hamburg, Germany
}

\begin{abstract}
Advanced research light sources, such as free-electron lasers, require ultra-precise and long $\mathrm{x}$-ray mirrors that provide high reflectivity, high flux and a wide wavelength range. An X-ray mirror is a combination of a substrate and a coating. The demand for large mirrors has increased during the last few years, since surface finishing technology is able to process longer substrate lengths on the rms-level of a few nanometers. A state-of-the-art X-ray mirror could be coated with more than one single layer to allow a selection of thin-film materials suitable for the large wavelength range of a free-electron laser. Presented here is an X-ray mirror fabrication method to achieve low variation in thickness of less than $1 \mathrm{~nm}$ (peak-to-valley) over the whole mirror length of about $1 \mathrm{~m}$. Low figure errors and low roughness are essential for a wave front preserving transport of photons and a high reflectance of a mirror surface. At FLASH II, the new extension of the Free-electron LASer in Hamburg (FLASH) at DESY, Germany, the wavelength range will be 4-80 nm. It is further expected that the photon beam will possess average single pulse energy of 1-500 $\mu \mathrm{J}$, pulse duration of 10-300 fs (FWHM), and peak power of 1-5 GW. At the Helmholtz-Zentrum Geesthacht, an in-house designed magnetronsputtering facility enabled us to deposit single layers and multilayers on up to $1.5 \mathrm{~m}$ long substrates. Earlier results confirmed the excellent uniformity of X-ray optical coating properties in the tangential and sagittal direction of the mirrors. Moreover, the deposition facility provided the simultaneous fabrication of two mirrors to achieve identical properties. Thin films of amorphous carbon $(\mathrm{a}-\mathrm{C})$, boron carbide $\left(\mathrm{B}_{4} \mathrm{C}\right)$ and nickel $(\mathrm{Ni})$ are deposited by means of magnetron sputtering. The thin-film properties were investigated and analyzed by means of X-ray reflectometry (XRR), atomic force (AFM), and interference microscopy. The experimental results were analysed using simulations for the determination of layer thickness, density and roughness.
\end{abstract}

Keywords: single layer mirrors, multilayer mirrors, X-ray mirrors, synchrotron sources, free-electron laser, X-ray freeelectron laser, magnetron sputtering, X-ray optics

\section{INTRODUCTION}

Currently, long X-ray mirrors are required at advanced research light sources in order to transport or shape the photon beam. The demands on the quality and finish of mirrors are severe at third generation storage-ring based X-ray sources. They are used as standard components for collimating, focusing and low-pass filtering ${ }^{1}$. At new diffraction-limited X-ray sources such as free-electron lasers (FEL) or storage-ring based, the demands on beamline optics will be and still are scientifically challenging. The technical requirements of X-ray mirrors are a challenge for both surface finishing and coating technology. Metrology measurement methods are nowadays at the limit, especially for the determination of the radius of upcoming X-ray mirrors, which are required for the European XFEL project ${ }^{2}$ in Hamburg/Germany. In this case a radius of curvature of more than $6000 \mathrm{~km}$ has to be determined. Furthermore, for the coating technology it will be a challenge to deposit single layers with a high level of uniformity over about 1 meter.

*michael.stoermer@hzg.de; phone 494152 87-2628; fax 494152 87-2636; hzg.de

Advances in X-Ray/EUV Optics and Components IX, edited by Christian Morawe,

Ali M. Khounsary, Shunji Goto, Proc. of SPIE Vol. 9207, 92070H · ㄷ 2014 SPIE

CCC code: $0277-786 \mathrm{X} / 14 / \$ 18 \cdot$ doi: $10.1117 / 12.2063017$ 
The technical specifications are extremely tight, especially the requirement that the shape error of the mirror be less than $2 \mathrm{~nm}$ peak-to-valley over the entire optical area. The achievable limits of substrate fabrication are continuously extended to establish very long and ultra-smooth substrates with low micro-roughness in various spatial frequency ranges ${ }^{3}$. The way of surface finishing of these high-quality substrates over a length of $1 \mathrm{~m}$ can be improved by contamination-free conditions. Mirror reflectivity can be reduced by both roughness and contamination of substrate or coating ${ }^{4}$. After surface finishing, a substrate is coated with a suitable film to change its surface according to the X-ray optical requirements of the desired application. The fabricated X-ray mirror (i.e. substrate and coating) should maintain important properties like the above-mentioned low roughness values which are first preset by the substrate surface. One expectation is that the coating process does not increase surface roughness or alter the surface morphology in such a way that mirror reflectivity is reduced.

In this article experimental results of two internationally unique X-ray mirrors are presented. These mirrors are to meet the requirements determined by the extension of FLASH II in the machine tunnel section. The mirrors are required to reflect the FEL beam with high reflectivity over a broad range of wavelengths. The main layer is amorphous carbon, which is well-known since almost all carbon coatings on optical elements at FLASH were prepared by the HZG sputtering facility ${ }^{5}$. On the two mirrors described here, carbon is accompanied by nickel and boron carbide. It was therefore necessary that three stripes of single layers be coated onto one mirror and this had to be repeated to create a double mirror with similar film properties. The width and length of the stripes were determined by the elliptical foot print of the X-ray beam. Then it will be possible to choose the best coating material with respect to the desired wavelength range.

\section{EXPERIMENTAL}

The X-ray mirror fabrication process was performed using a $4.5 \mathrm{~m}$ long in-house designed sputtering facility at HZG. The current challenge highlighted in this article is that two $820 \mathrm{~mm}$ long Si blanks should be coated by three single layers side-by-side. A mirror with such a stripe pattern is required in the FLASH II tunnel ${ }^{6-8}$. Before deposition onto the $820 \mathrm{~mm}$ long Si substrates, a lot of short calibration samples were coated over various areas to determine X-ray optical film properties such as thickness, density and roughness. The sputtering facility ${ }^{9}$ enables us to coat a lot of substrates fixed on a carrier over an area of $1500 \mathrm{~mm}$ x $120 \mathrm{~mm}$. Furthermore, the positions and dimensions of the required stripes of single layers were measured, controlled and adjusted to fulfill the technical requirements as mentioned below. For the thin-film preparation, an ultra-high vacuum chamber with rectangular and circular magnetron sputtering sources is employed. The base pressure is less than $10^{-5} \mathrm{~Pa}$. The available sputtering modes are DC, MD and RF. Here, the power used at the generator was 80-800 W. The argon working gas pressure was in the range of 0.1 to $0.5 \mathrm{~Pa}$.

Two long mirrors are positioned inside the FLASH II tunnel for two main purposes: radiation safety and correction of pointing instabilities. As first optical elements positioned at the end of the FLASH II machine tunnel, the mirror pair causes a horizontal photon beam off-set and thus separates the FEL beam from the Bremsstrahlung background. Therefore, only the FEL beam is transported into the new FLASH II experimental hall. Secondly, placed in newly designed mirror chambers system ${ }^{8}$, the mirror pair will compensate for different photon beam pointing generated by special machine conditions. Placed $20 \mathrm{~m}$ from a FEL source an angle of grazing incidence of 1 degree is required to protect the optical surfaces from damage by the intense photon beam. Considering a transported beam size of $\sigma$ and a wavelength of $40 \mathrm{~nm}$, a mirror length of $800 \mathrm{~mm}$ is needed. The chosen coating materials are selected for best and stable mirror reflectivity and the use of the $3^{\text {rd }}$ and $5^{\text {th }}$ harmonic of an FEL beam was taken into account. The main layer of carbon is for the fundamental wavelengths from $4.6 \mathrm{~nm}$ to $80 \mathrm{~nm}$, Nickel is suitable for wavelengths from $1.8 \mathrm{~nm}$ to 4.6 $\mathrm{nm}$ and boron carbide can be used from $0.8 \mathrm{~nm}$ to $1.8 \mathrm{~nm}$. The expected mirror reflectivity is above $90 \%$ and the range is below 3\% over the above-mentioned wavelengths using IMD simulations with experimentally achievable properties by means of magnetron sputtering. The widths of the layers represent $6 \sigma\left(\mathrm{Ni}\right.$ and $\left.\mathrm{B}_{4} \mathrm{C}\right)$ or 2 times $6 \sigma(\mathrm{a}-\mathrm{C})$ of the expected largest beam size in the working regimes.

The calibration samples are well-polished Si (100)-wafer substrates with $20 \mathrm{~mm}$ x $60 \mathrm{~mm}$ x $0.64 \mathrm{~mm}$. The final mirrors for FLASH exhibit the following properties: the dimensions are $820 \mathrm{~mm}$ x $80 \mathrm{~mm}$ x $80 \mathrm{~mm}$. The weight of a mirror is 12 $\mathrm{kg}$. The radii are specified to be larger than $100 \mathrm{~km}$ in the tangential and larger than $50 \mathrm{~km}$ in the sagittal direction. The two plane X-ray mirrors are needed in the FLASH II tunnel section. The important X-ray optical parameters for deposition are the following: The optical area should be coated with three single layers of $\mathrm{Ni}, \mathrm{C}$, and $\mathrm{B}_{4} \mathrm{C}$. The film 
thickness should be in the range from 35 to $45 \mathrm{~nm}$. The central stripe of amorphous carbon is specified with $20 \mathrm{~mm} \mathrm{x}$ $800 \mathrm{~mm}$. The outer stripes of $\mathrm{Ni}$ and $\mathrm{B}_{4} \mathrm{C}$ should be at least $8 \mathrm{~mm}$ in width and the same length.

The single layers were investigated by means of X-ray reflectometry using Cu radiation (X-ray wavelength of $0.154 \mathrm{~nm}$ ). A diffractometer D8 Advance (Bruker) was equipped with a reflectometry stage and a knife edge. A Göbel mirror behind the source was used to shape a parallel and monochromatic beam. All measurements were performed on short calibration samples. Some XRR measurements were performed with a rectangular slit of $2 \mathrm{~mm} \times 2 \mathrm{~mm}$ at various y-positions in intervals from one side to the other in the sagittal direction of the mirror in order to determine the position of the stripe and the transition zone between stripes. The reflectivity scans were analyzed with the Bruker simulation software REFSIM and LEPTOS R. Some selected scans were also simulated by David Windt's IMD software ${ }^{10}$.

Micro-roughness measurements were performed using atomic force microscopy and white-light interferometry. Atomic force microscopy is a scanning probe microscopy technique providing height resolution on atomic scale ${ }^{11,12}$. It is a surface sensitive method that probes real space lengths, which is complementary to the $\mathrm{X}$-ray scattering. The instrument used was a Bruker SIS-Ultra-objective AFM with a $40 \mu \mathrm{m}$ x $40 \mu \mathrm{m}$ scanner. The instrument is based on a PICO-station system with an active vibration damping. The tip applied for these measurements was a silicon SPM-sensor for the noncontact mode with resonance frequency of $190 \mathrm{kHz}$ and force constant of $48 \mathrm{~N} / \mathrm{m}$. The tip is shaped like a polygon based pyramid with a height of 10-15 $\mu \mathrm{m}$. The tip radius was less than $8 \mathrm{~nm}$. Thus, the achievable lateral resolution was in the range of about $20 \mathrm{~nm}$. After 10 scans the tip was changed to avoid measurements being influenced by tip wear. Whitelight interferometry, as a second method with higher spatial frequency, was also used to measure the micro-roughness of three coatings and uncoated silicon. A WYKO NT1100 was employed with two Mirau-type interferometer objectives studying micro-roughness on a spatial wavelength range from $310 \mu \mathrm{m}$ to $1.7 \mu \mathrm{m}$ (magnification of 20x) and from $94 \mu \mathrm{m}$ to $0.62 \mu \mathrm{m}$ (magnification of 50x).

\section{RESULTS AND DISCUSSION}

\subsection{Thickness uniformity of single layers}

Excellent uniformity in thickness of the required three layers is essential for FEL applications. The mean coating thickness is specified to be in the range from $35-45 \mathrm{~nm}$, although it must be taken into consideration that the tolerances and variation in thickness should be below $4 \%$ (rms) over the whole mirror aperture of about $800 \mathrm{~mm}$. This tolerance corresponds to an acceptable thickness variation of less than $1.6 \mathrm{~nm} \mathrm{rms}$ at a typical thickness of $40 \mathrm{~nm}$. The experimental layer thicknesses of $\mathrm{Ni}, \mathrm{C}$, and $\mathrm{B}_{4} \mathrm{C}$ in the tangential direction over the whole mirror length of $1500 \mathrm{~mm}$ are shown in Figure 1. All measurements were performed on small calibration samples of silicon wafers. The mean, rms and peak-to-valley (PV) values are tabulated in the table 1 . All PV values are below $1 \mathrm{~nm}$ and all rms values are below 0.3 $\mathrm{nm}$ in the tangential direction. Since the mean layer thicknesses are higher than $45 \mathrm{~nm}$ for $\mathrm{Ni}$ and $\mathrm{B}_{4} \mathrm{C}$ and lower than 35 $\mathrm{nm}$ for $\mathrm{C}$, it has to be changed in the final deposition according to the specified thickness range. The measured high level of uniformity confirms former results using the HZG magnetron sputtering facility ${ }^{5}{ }^{9}$.Previous investigations of tungsten and carbon coatings reached similar uniformity in thickness. Here, the goal was to coat a very large aperture of $1500 \mathrm{~mm}$ x $120 \mathrm{~mm}$. Additional mask technology was developed and optimized in order to achieve a high uniformity over the whole optical area, especially in the sagittal direction of a mirror.

The current results are achieved after a three-step deposition of $\mathrm{Ni}, \mathrm{C}$, and $\mathrm{B}_{4} \mathrm{C}$. Before each step, two covers were adjusted at the carrier in such a way that each stripe was coated in a distinct height above the bottom of the carrier and with a certain width. After optimization and precise adjustment, the first of two mirrors were coated with three stripes side-by-side. The coating process of each material is slightly different and required certain conditions of Ar gas pressure, generator power and carrier velocity. Parameters used for the deposition of $\mathrm{Ni}, \mathrm{C}$, and $\mathrm{B}_{4} \mathrm{C}$ are mentioned in the second paragraph. It is important to note that this procedure is interrupted twice by a vacuum break. Therefore, a sequence was chosen in order to avoid the coverage of a heavier element onto a lighter element during deposition. A wrong material on top of a layer would lead to a reduction of X-ray reflectivity. The chosen path was as follows: the first stripe was nickel, second boron carbide and the last was carbon. After coating the first mirror, the second one was coated using the same deposition parameters and vacuum conditions to achieve the same film properties. The achieved final results on two 820 $\mathrm{mm}$ long mirrors are verified using short witness samples during both processes. 


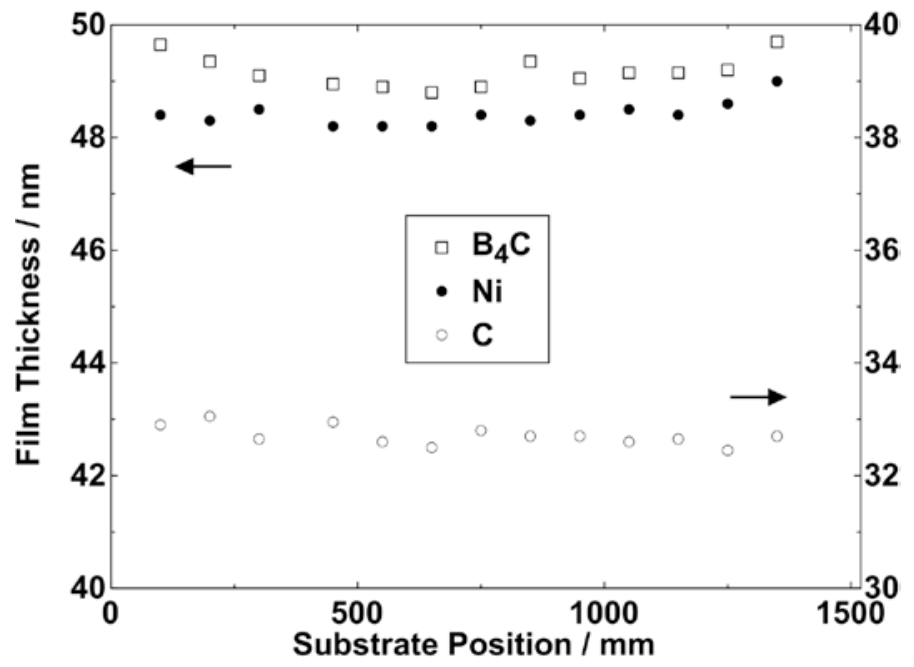

Figure 1. Film thickness of single layers of $\mathrm{Ni}, \mathrm{C}$, and $\mathrm{B}_{4} \mathrm{C}$ as a function of the substrate position, i.e. the tangential direction of the mirror, measured by $\mathrm{X}$-ray reflectometry using $\mathrm{Cu}$ radiation.

Table 1. Measured film thickness (in $\mathrm{nm}$ ) and roughness values (in $\mathrm{nm} \mathrm{rms}$ ) of $\mathrm{Ni}$, C, and $\mathrm{B}_{4} \mathrm{C}$ layers; all measurements were performed on small calibration samples (roughness values of uncoated silicon substrates are added for comparison).

\begin{tabular}{|c|c|c|c|c|}
\hline & Uncoated Si & $\begin{array}{c}\text { Coating of } \\
\text { nickel }\end{array}$ & $\begin{array}{c}\text { Coating of } \\
\text { carbon }\end{array}$ & $\begin{array}{c}\text { Coating of } \\
\text { boron } \\
\text { carbide }\end{array}$ \\
\hline Mean thickness / nm & - & 48.4 & 32.7 & 49.2 \\
\hline $\begin{array}{l}\text { Variation in thickness / } \\
\mathrm{nm} \\
\text { (rms / peak-to-valley) }\end{array}$ & - & $0.22 / 0.8$ & $0.17 / 0.6$ & $0.28 / 0.9$ \\
\hline $\begin{array}{l}\text { Percentage variation in } \\
\text { thickness }\end{array}$ & - & 1.7 & 1.8 & 1.8 \\
\hline $\begin{array}{l}\text { Roughness / nm rms } \\
\text { (WLI, 20x) }\end{array}$ & $0.51-0.57$ & $0.72-0.86$ & $0.58-0.64$ & $0.52-0.77$ \\
\hline $\begin{array}{l}\text { Roughness / nm rms } \\
\text { (WLI, 50x) }\end{array}$ & $0.43-0.56$ & $0.36-0.43$ & $0.40-0.43$ & $0.41-0.62$ \\
\hline $\begin{array}{l}\text { Roughness / nm rms } \\
(\mathrm{AFM}, 10 \mu \mathrm{m} \times 10 \mu \mathrm{m})\end{array}$ & $0.21-0.23$ & $0.14-0.16$ & $0.10-0.11$ & $0.23-0.24$ \\
\hline $\begin{array}{l}\text { Roughness / nm rms } \\
\text { (AFM, } 1 \mu \mathrm{m} \text { x } 1 \mu \mathrm{m})\end{array}$ & $0.18-0.20$ & $0.14-0.17$ & $0.11-0.13$ & $0.23-0.25$ \\
\hline
\end{tabular}




\subsection{Stripe pattern of three layers}

The use of two covers, fixed at the carrier and parallel to the tangential direction of the mirror, provides the opportunity to coat a stripe (i.e. a defined aperture section) on to a substrate. Typical distributions of the thickness of single layers of $\mathrm{B}_{4} \mathrm{C}$ around their center are shown in Figure 2. Four certain settings of covers are used for improvement. All thickness measurements were performed with a rectangular slit of $2 \mathrm{~mm} \times 2 \mathrm{~mm}$ at various y-positions near the center of each stripe. The first setting employed two covers of $2 \mathrm{~mm}$ thick stainless steel (open squares). A rounded thickness profile symmetrically around the maximum thickness in the middle was obtained. At the bottom the profile is expanded to a wide foot, which can be explained by the very broad deposition profile of the rectangular sputtering source. The length of the sputtering source parallel to y is about $30 \mathrm{~cm}$, which is quite large in comparison to the stripe width of $16 \mathrm{~mm}$. The thickness of the covers with $2 \mathrm{~mm}$ causes shadowing. Moreover, the distance between cover and substrate of about $2 \mathrm{~mm}$ is most likely responsible for the foot at the edge of the stripe. There is also a small amount of coating material coated under the cover. The broadening is due to collisions of target and argon atoms along the way to the substrate. In order to reduce the uncoated area between the stripes, so called dead zone, some improvements are required. The edge of the 1.6 $\mathrm{m}$ long covers was tapered in a second setting, so that a long chamfer ends at a $0.5 \mathrm{~mm}$ thick edge. Therefore, the uniform area in the middle of the stripe was distinctly broadened. The normalized thickness is distinctly above $90 \%$ over the whole width of the stripe by the use of the improved covers (solid squares). A trapezoidal cross-section of the stripe is determined with a measuring step width of $2 \mathrm{~mm}$. After reduction of the distance between cover and substrate to approximately $1.5 \mathrm{~mm}$, the foot at the edge of the stripe vanished in a third setting (red squares). The last optimization was to adjust the width of the covers to the specified width of the stripe for the final deposition. A perfect positioning of the mask resulted in a stripe width of about $8 \mathrm{~mm}$ (solid circles). Finally, the two FLASH mirrors were coated under these optimized conditions in order to achieve a nearly rectangular-shaped thickness distribution in the sagittal direction of the mirror. Future improvements are expected due to the use of foils that reduce the distance to zero without damaging the mirror surface. In case of contact it should be possible to achieve a very small transition zone and high uniformity.

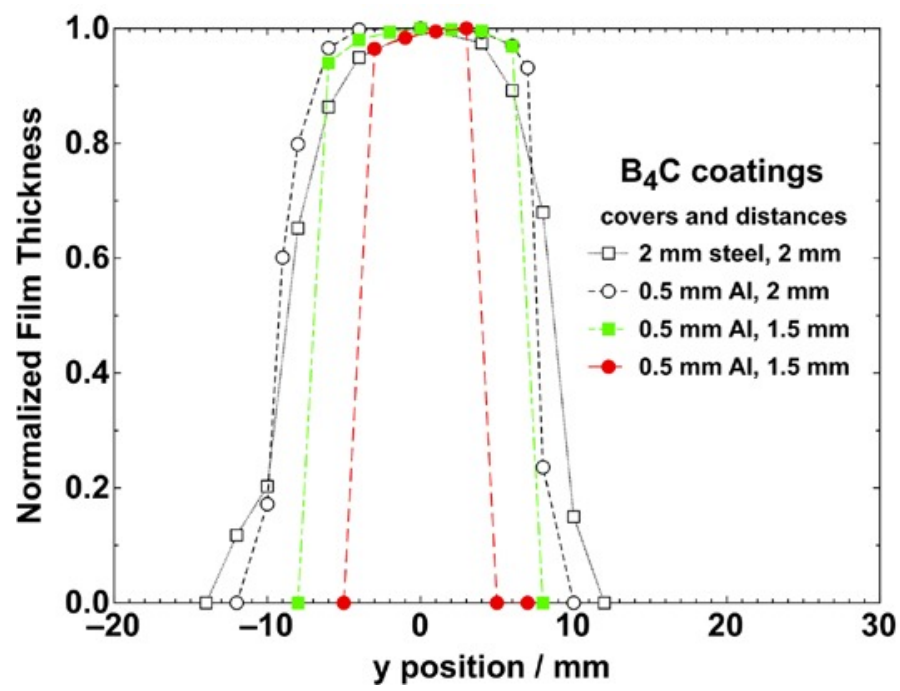

Figure 2. Normalized film thickness as a function of the y position located around the center of the coating stripe, four settings of various covers and distances to the mirror surface are shown.

Figure 3 shows a typical distribution of the film thickness of three single layers of $\mathrm{Ni}, \mathrm{C}$, and $\mathrm{B}_{4} \mathrm{C}$ as a function of the $\mathrm{y}$ position, which means from side to side in the sagittal direction of the mirror. The optimization resulted in a perfect stripe pattern of three materials. The Ni coating extends from $52 \mathrm{~mm}$ to $64 \mathrm{~mm}$ and its center is at $58 \mathrm{~mm}$. The center of the a-C coating in the middle is $75 \mathrm{~mm}$, which fulfills the specified difference precisely. The center of the $\mathrm{B}_{4} \mathrm{C}$ coating is again shifted by $17 \mathrm{~mm}$ to a y position of $92 \mathrm{~mm}$. It can be stated that each material is distinctly separated on the optical area. Therefore, a contamination of a former coated layer of a latter one during the deposition can most likely be excluded. A change of the coating material is possible by a side-step of about $17 \mathrm{~mm}$. An exchange of a mirror in the tunnel section is a time consuming task due to a vacuum break, which would concern all beamlines at the FEL. 
For each coating a distinct width between the covers was adjusted before deposition. In the case of $\mathrm{Ni}$, $\mathrm{C}$, and $\mathrm{B}_{4} \mathrm{C}$ the cover width was chosen to be $10 \mathrm{~mm}, 21 \mathrm{~mm}$ and $9 \mathrm{~mm}$, respectively. This last stage of pattern optimization before final deposition is shown in Figure 3. Additionally, an intermediate step was done in order to evaluate the experimental result of the achieved stripe pattern on a more realistic surface. A short silicon blank called "little brother" was therefore coated in three runs one after another. Figure 4 shows an image of the prototypical silicon blank with the same cross-section as the long final mirrors and a reduced length of $120 \mathrm{~mm}$. This additional experiment distinctly confirmed the whole threestep process. For the final deposition of the first of two $820 \mathrm{~mm}$ long mirrors, the width between the covers was again slightly increased by a tenth of a millimeter in order to extend the coated stripe at the expense of the uncoated area. Thus, the dead zone between two adjacent stripes was about $2 \mathrm{~mm}$ or less along the whole mirror length of 1 meter. Then, the experimentally achieved stripe widths are wider than the specified values for $\mathrm{Ni}, \mathrm{C}$, and $\mathrm{B}_{4} \mathrm{C}$ of $8 \mathrm{~mm}, 20 \mathrm{~mm}$ and $8 \mathrm{~mm}$, respectively, and their stripe centers are well located relative to each other with a distance of approximately $17 \mathrm{~mm}$ to the center of the central stripe of the a-C coating. X-ray mirror fabrication is based on the assumption that the coating properties of the calibration steps on small Si-wafer samples can be transferred to and repeated in the final coating on very long substrates. The stability and reproducibility of the sputtering facility are therefore very important and essential for the current success and future development projects. It is clear that it is demanding to investigate the coating properties on the final X-ray optics due to their length and weight. Therefore, small witness samples are used to control the achieved layer properties with respect to their X-ray optical properties such as thickness, density and roughness.

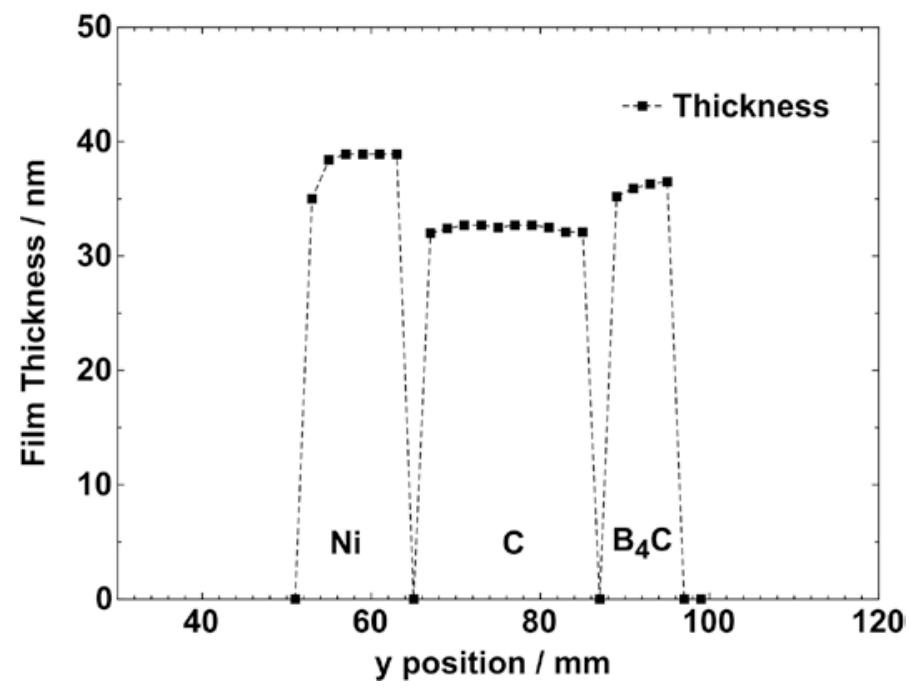

Figure 3. Thickness variation of three stripes of $\mathrm{Ni}, \mathrm{C}$ and $\mathrm{B}_{4} \mathrm{C}$ layers along the sagittal direction of the mirror. Stripe pattern is prepared in three coating runs one after another. Each coating run required a distinct position of the two covers.

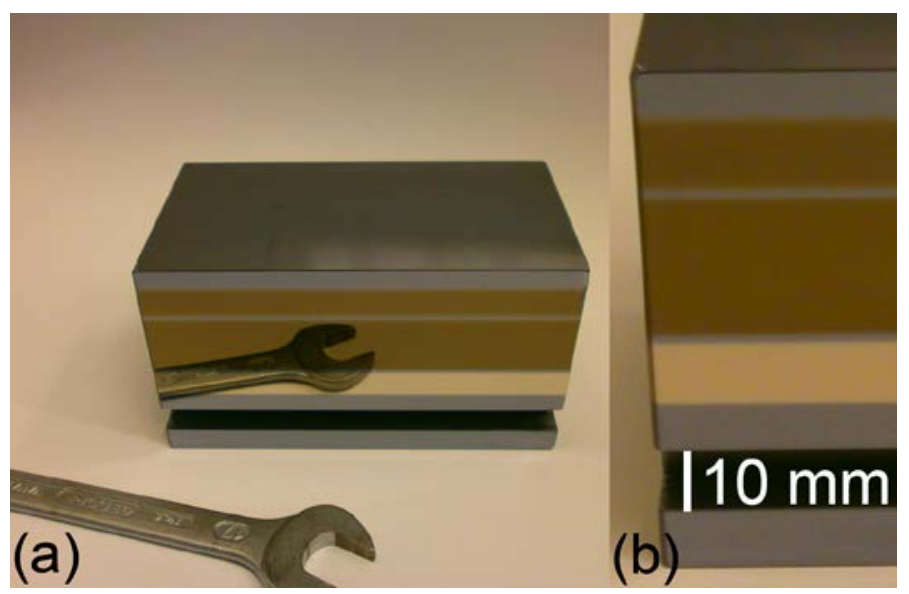

Figure 4. Image of a silicon blank coated as a prototype before the final deposition. The insert shows the perfect positioning of the three stripes to each other. 
Reproducibility, stability and precision of the sputtering process were studied intensively over the last years. Former and current experimental results of carbon coatings are compared in Figure 5 that demonstrates three $1.5 \mathrm{~m}$ long coatings of amorphous carbon prepared during the last 7 years. The measured layer thickness, normalized by the mean value as a function of the substrate position, depicted the level of the uniformity of the coating process. The density of measuring points was different due to various requirements over the last years. However, the important result is that there is no important change during time. The mean thickness was $45.4 \mathrm{~nm}, 44.2 \mathrm{~nm}$ and $32.7 \mathrm{~nm}$. For all three cases a peak-tovalley thickness variation is about $1 \mathrm{~nm}$ and even better, the corresponding rms values are of $0.3 \mathrm{~nm}$ and below. It can be stated that the HZG sputtering facility has provided a good stability and extraordinary reproducibility in X-ray optical properties since it started its operation in 2007.

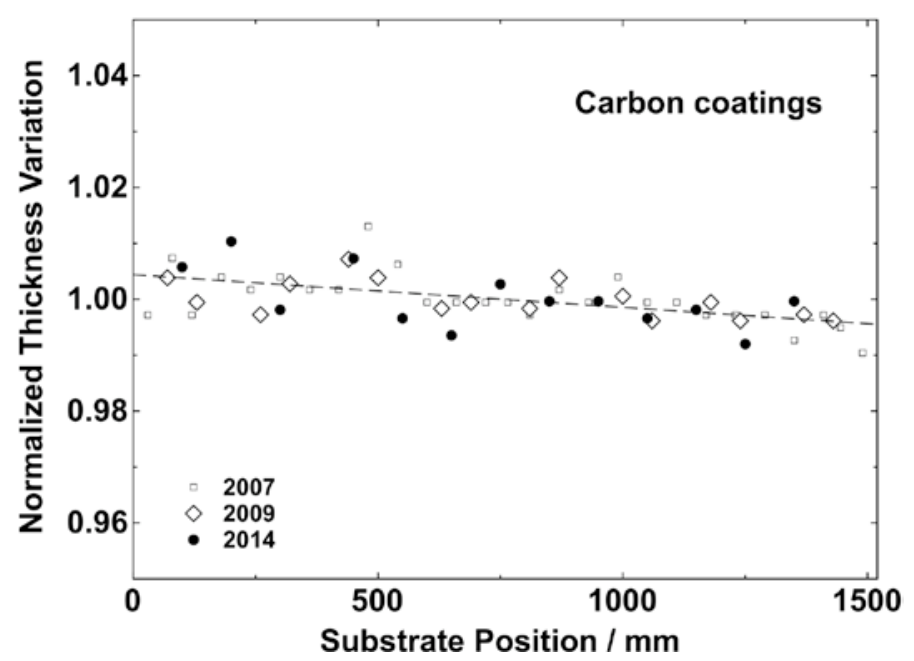

Figure 5. Normalized thickness variation of three carbon coatings prepared in recent years. The mean thickness of these layers was $30-45 \mathrm{~nm}$. The peak-to-valley value is less than $1 \mathrm{~nm}$ and the rms value is less than $0.3 \mathrm{~nm}$.

Micro-roughness of single layers of $\mathrm{Ni}, \mathrm{C}$, and $\mathrm{B} 4 \mathrm{C}$ were investigated on final calibration samples using atomic force microscopy (AFM) and white-light interferometry (WLI). In Figure 6 a-d, four representative AFM images over a measuring area of $1 \mu \mathrm{m} \times 1 \mu \mathrm{m}$ of uncoated and coated silicon are shown. Additional AFM measurements were performed on a larger area of $10 \mu \mathrm{m} \times 10 \mu \mathrm{m}$. All data is listed in Table 1. All roughness values are below $0.9 \mathrm{~nm} \mathrm{rms}$. The uncoated state of Si exhibits roughness values of $0.2 \mathrm{~nm}$ rms and 0.5-0.6 nm rms measured by AFM and WLI, respectively. It is important to note that $820 \mathrm{~mm}$ long uncoated mirrors exhibit a significant better quality of microroughness than the calibration sample used here to check the coating process. In the AFM image of $\mathrm{B}_{4} \mathrm{C}$ (Fig. 6 top right), it is distinctly visible that the surface morphology of the film is similar to the one of the underlying silicon substrate (Fig. 6 top left). The $\mathrm{B}_{4} \mathrm{C}$ coating seems to maintain the morphology of Si. By coating of a-C and Ni (Fig. 6 bottom left and right), a perfect coverage of the Si surface is obtained. Here, the film surface seems to be more flat and totally wet the underlying substrate. This is indicated by the measured roughness on a small scale, since it resulted in very low values of less than $0.2 \mathrm{~nm}$. Especially in the case of a-C coatings, the film roughness can be improved drastically. The roughness values measured by white-light interferometry were not so evident. In general, it can be stated that the deposition process replicates the substrate roughness. In fact, it rather tends to a slight improvement of roughness. 

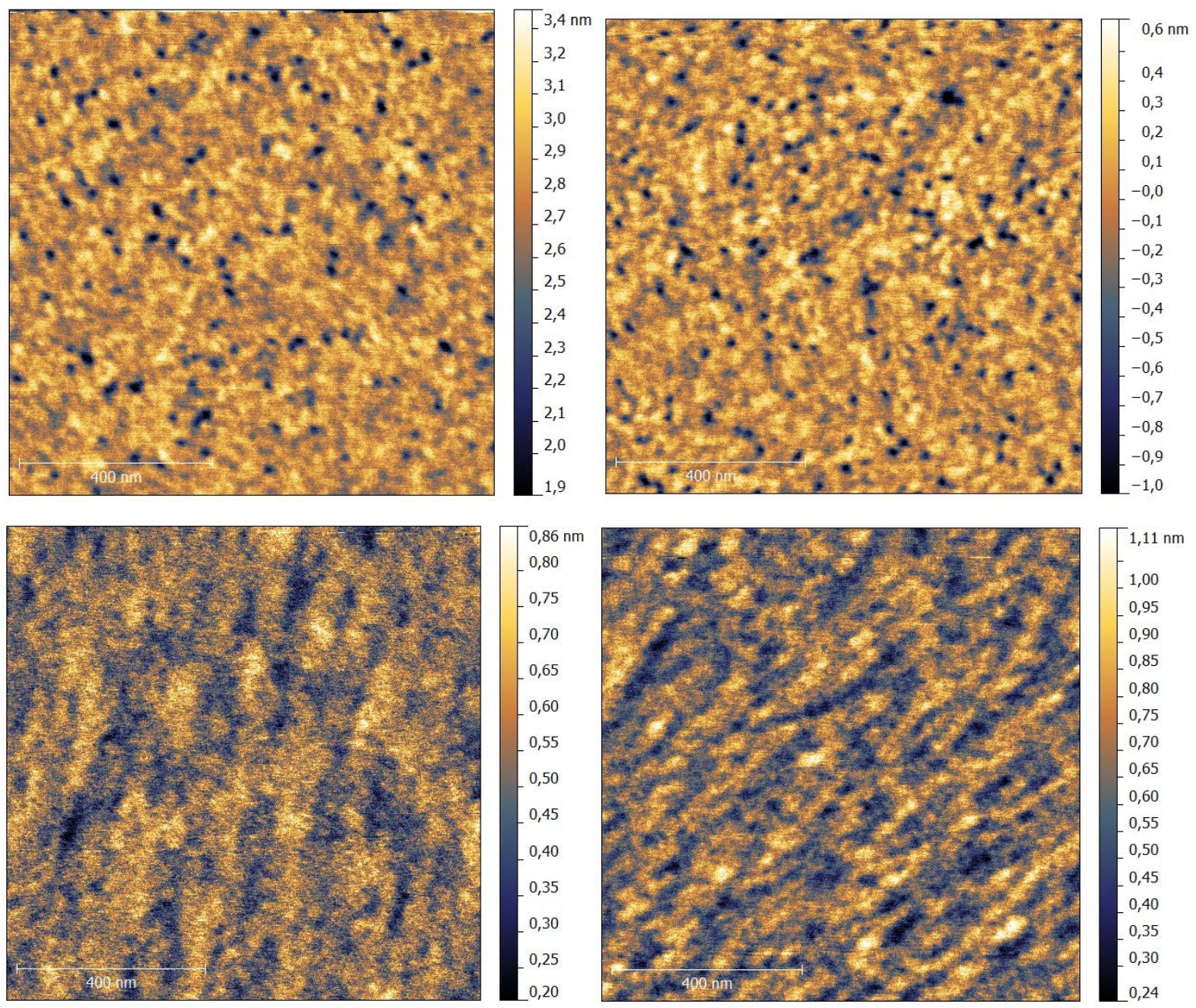

Figure 6. Micro-roughness measurements of uncoated silicon (top left) and single layers of $\mathrm{B}_{4} \mathrm{C}$ (top right), a-C (bottom left) and $\mathrm{Ni}$ (bottom right), measured with an atomic force microscope on a measuring area of $1 \mu \mathrm{m} \times 1 \mu \mathrm{m}$.

\section{CONCLUSIONS}

Very long X-ray mirrors are required for beam transport, shaping or imaging at free-electron lasers (FEL) and synchrotron sources. Two $820 \mathrm{~mm}$ long substrates were coated with three single layers of $\mathrm{B}_{4} \mathrm{C}$, a-C and $\mathrm{Ni}$ for the tunnel section of FLASH using the HZG magnetron sputtering facility. The coating properties were investigated with respect to the thickness uniformity and micro-roughness of the single layers and the stripe pattern of three layers. Reproducibility, precision and stability of the sputtering facility were examined and discussed. Finally, it can be stated that it is possible to coat single layers with a high level of uniformity and precision. Along a mirror length of about $1 \mathrm{~m}$, a variation in thickness was achieved of less than $0.3 \mathrm{rms}$, i.e. less than $1 \mathrm{~nm}$ peak-to-valley. This experimental result has been achieved safely and has proved to be repeatable over the last 7 years. 


\section{ACKNOWLEDGEMENTS}

We are grateful to the engineering department at HZG for their important support during the maintenance and improvement of the HZG magnetron facility, especially to Jürgen Buhrz for software support, Gerd Musielak for fruitful maintenance and important adjustment, Christian Horstmann and Gregor Nowak for general help and basic technical support at the facility and all for the successful cooperation.

\section{REFERENCES}

[1] http://science.energy.gov/ /media/bes/pdf/reports/files/BES_XRay_Optics_rpt.pdf

[2] Sinn, H. et al., [Conceptual Design Report: X-ray Optics and Beam Transport], European XFEL, Hamburg, 3114 (2011)

[3] Siewert, F.; "Metrology, mirrors and gratings - advances and challenges in synchrotron optics," Journal of Physics: Conference Series 425, 152001 (2013).

[4] VDI/VDE guideline, X-ray optical systems VDI/VDE 5575, Part 4: X-ray mirrors, Berlin, Beuth Verlag (2011).

[5] Störmer, M., Siewert, F., Gaudin, J., "Development of X-ray optics for advanced research light sources,” Proc. SPIE 8078, 80780G (2011).

[6] Tiedtke, K., Azima, A., von Bargen, N., Bittner, L., Bonfigt, S., Duesterer, S., Faatz, B., Fruehling, U., Gensch, M., Gerth, Ch., Guerassimova, N., Hahn, U., Hans, T., Hesse, M., Honkavaar, K., Jastrow, U., Juranic, P., Kapitzki, S., Keitel, B., Kracht, T., Kuhlmann, M., Li, W. B., Martins, M., Nunez, T., Ploenjes, E., Redlin, H., Saldin, E. L., Schneidmiller, E. A., Schneider, J. R., Schreiber, S., Stojanovic, N., Tavella, F., Toleikis, S., Treusch, R., Weigelt, H., Wellhoefer, M., Wabnitz, H., Yurkov, M. V., Feldhaus, J., "The soft X-ray freeelectron laser FLASH at DESY: beamlines, diagnostics and end-stations,“ New Journal of Physics, 11, 023029 (2009).

[7] Faatz B., Baboi, N., Ayvazyan, V., Balandin, V., Decking, W., Duesterer, S., Eckoldt, H.-J., Feldhaus, J., Golubeva, N., Honkavaara, K., Koerfer, M., Laarmann, T., Leuschner, A., Lilje, L., Limberg, T., Noelle, D., Obier, F., Petrov, A., Ploenjes, E., Rehlich, K., Schlarb, H., Schmidt, B., Schmitz, M., Schreiber, S., SchulteSchrepping, H., Spengler, J., Staack, M., Tavella, F., Tiedtke, K., Tischer, M., Treusch, R., Vogt, M., Willner, A., Bahrdt, J., Follath, R., Gensch, M., Holldack, K., Meseck, A., Mitzner, R., Drescher, M., Miltchev, V., Roensch-Schulenburg, J., Rossbach, J., "Flash II: Perspectives and challenges,” Nucl. Meth. Instrum. A635(1), S2-5 (2011).

[8] Kuhlmann, M., Plönjes, E., "FLASH 2 Photondiagnostics and beamline concepts,” Proc. SPIE 8778, 87781A (2013).

[9] Störmer, M., Horstmann, C., Siewert, F., Scholze, F., Krumrey, M., Hertlein, F., Matiaske, M., Wiesmann, J., and Gaudin, J., "Single-layer mirrors for advanced research light sources," Proc. AIP 1234, 756-759 (2010).

[10]Windt, D.L., "IMD-Software for modelling the optical properties of multilayer films," Computers in Physics 12(4), 360-370 (1998).

[11]Binnig, G., Quate, C.F., Gerber, C., “Atomic Force Microscope,” Phys. Rev. Lett. 56(9), 930-933 (1986).

[12] Meyer, E., “Atomic Force Microscopy,” Progress in Surface Science, 41(1), 3-49 (1992). 